\title{
Implementasi Sistem Business Intelligence Untuk Data Penelitian di Perguruan Tinggi
}

\author{
Firman Noor Hasan \\ Teknik Informatika Universitas Muhammadiyah Prof. Dr. Hamka \\ Jl. Tanah Merdeka No.6, Pasar Rebo, Jakarta Timur Telp: 021-8778.2739, Mobile: 0813.1140.6664 \\ Website: www.ft.uhamka.ac.id, E-mail: firman.noorhasan@uhamka.ac.id
}

\begin{abstract}
Abstrak - Data didalam sebuah perguruan tinggi merupakan aset, aset yang senantiasa berkembang dan membutuhkan pengelolaan secara khusus, baik dari sisi pemanfaatannya maupun dari sisi penyimpanannya. Pembangunan business intelligence merupakan salah satu cara untuk dapat mengekstrak informasi penting di sebuah perguruan tinggi. Kondisi sistem yang berjalan saat ini di Perguruan Tinggi XYZ yaitu laporan tentang data-data penelitian belum mempunyai database dan hanya dihasilkan langsung dengan file yang berbentuk excel, dan setiap program studi mempunyai format yang berbedabeda. Oleh karena itu dibutuhkan sistem business intelligence yang perancangannya meliputi perancangan data warehouse, perancangan olap analysis, perancangan report, dan perancangan dashboard. Penelitian ini menghasilkan sebuah sistem business intelligence di Perguruan Tinggi XYZ yang sangat membantu didalam mengumpulkan data-data penelitian sehingga dapat dianalisis. Report yang dirancang sangat membantu didalam membuat laporan penelitian dan dapat disesuaikan dengan kebutuhan, sehingga masalah yang sering terjadi dalam hal kebergantungan dalam perolehan laporan diharapkan tidak terjadi kembali. Dashboard penelitian yang dirancang membantu pimpinan didalam menganalisis data untuk mempelajari tren penelitian yang dilakukan di Perguruan Tinggi XYZ, serta dapat dijadikan untuk mendukung pengambilan keputusan dan nantinya dapat juga sebagai pengukur kinerja dosen.
\end{abstract}

Kata kunci: business intelligence, data warehouse, olap analysis, dashboard.

\section{PENDAHULUAN}

Data merupakan sebuah aset yang sangat berharga didalam sebuah perguruan tinggi, yang membutuhkan pengelolaan secara khusus, baik dari sisi pemanfaatan maupun dari sisi penyimpanannya [1]. Data dapat menjadi informasi yang sangat berguna didalam organisasi, untuk dapat memutuskan suatu kebijakan, melakukan suatu aksi-aksi strategis, atau didalam pengambilan suatu keputusan yang menyangkut tentang bisnis [1]. Namun didalam pemanfaatan untuk dapat mendukung pengambilan keputusan tersebut, selama ini prosesnya masih dilakukan secara manual. Pembangunan business intelligence merupakan salah satu cara untuk dapat mengekstrak informasi penting di sebuah perguruan tinggi [2]. Dengan adanya sistem business intelligence, yang akan dibangun, maka pengambilan keputusan dan strategi-strategi yang akan dilakukan oleh pimpinan Perguruan Tinggi XYZ dapat lebih mudah dilakukan. Hal ini dimungkinkan karena adanya data warehouse yang dibangun dapat menangani data eksternal, sumber datanya menjadi jelas, sehingga dapat melihat data secara lebih rinci, dan analisis terhadap data-data penelitian dapat dilakukan dengan lebih cepat, lebih efektif dan lebih efisien, salah satu manfaat dari data warehouse yaitu juga dapat digunakan untuk mengukur kinerja dari sebuah perguruan tinggi didalam menghadapi sebuah proses akreditasi atau yang biasa disebut Evaluasi Diri Perguruan Tinggi [3].

Sistem business intelligence didalam perguruan tinggi dirancang untuk dapat membantu institusi dalam menunjang proses Tridarma Perguruan Tinggi, yaitu pendidikan \& pengajaran, pengabdian pada masyarakat, dan penelitian. Penelitian merupakan salah satu tugas pokok perguruan tinggi, yang diharapkan untuk dapat memberikan kontribusi dan manfaat kepada proses pembelajaran, dan juga pengembangan ipteks, serta peningkatan terhadap mutu kehidupan di sebuah masyarakat. Program studi mempunyai akses yang luas terhadap fasilitas yang digunakan untuk penelitian oleh dosen maupun mahasiswa yang menunjang pelaksanaan penelitian untuk dapat mewujudkan visi misi dari sebuah program studi dan perguruan tinggi [4]. Program studi, Dosen, mahasiswa terlibat secara aktif didalam melaksanakan penelitian yang bermutu yang berorientasi kepada pengembangan ilmu. Hasil 
penelitian didiseminasikan melalui presentasi ilmiah dalam forum ilmiah nasional dan internasional dan atau dipublikasikan didalam jurnal nasional maupun internasional yang terakreditasi Dikti dan terindeks secara internasional [4].

Business intelligence mempunyai pendekatan analisis data yaitu yang sering disebut dengan OLAP (On-Line Analytical Processing) yang memungkinkan permintaan proses analisis yang bersifat dimensional dapat dilakukan secara cepat untuk tujuan analisis. OLAP juga dapat digunakan untuk menganalisis suatu data menjadi sebuah informasi yang nantinya akan digunakan untuk pengambilan keputusan pada Perguruan Tinggi XYZ [5]. Selanjutnya data peneltian didalam data warehouse diproses sehingga dapat ditampilkan pada dashboard sistem business intelligence universitas [6].

Sistem business intelligence yang akan dibangun di Perguruan Tinggi diharapkan untuk dapat dijadikan sebagai pendukung dalam pengambilan keputusan dengan menghadirkan data warehouse dari penelitian dan laporan analisis kegiatan penelitian yang telah dilakukan dan menyediakan sumber data yang terpusat sehingga dapat diakses oleh program studi, sehingga nantinya dapat menyediakan informasi yang dibutuhkan serta dapat menganalisa dan dengan cepat memperoleh hasil untuk dapat digunakan didalam pengambilan keputusan yang menyangkut akreditasi [7].

Pada penelitian ini dilakukan implementasi sistem business intelligence untuk data-data penelitian yang ada di sebuah perguruan tinggi swasta di Jakarta. Perancangan sistem business intelligence ini mengacu pada standar yang dijelaskan oleh Vercellis, sedangkan perancangan data warehouse dengan menerapkan nine-step methodology oleh Ralph Kimball [8][9]. Perangkat lunak yang digunakan untuk membangun sistem business intelligence didalam penelitian ini yaitu dengan memanfaatkan perangkat lunak berbasis open source (kode terbuka), yaitu Pentaho Data Integration (PDI) digunakan untuk perancangan data warehouse data-data penelitian, Mondrian OLAP (Online Analytical Processing) digunakan untuk perancangan OLAP, Pentaho Report Designer (PRD) digunakan untuk perancangan laporan data-data penelitian, Pentaho Community Dashboard Editor (Pentaho CDE) yang digunakan merancang dashboard untuk menampilkan data-data penelitian.

\section{LANDASAN TEORI}

Sistem business intelligence mengolah data sumber menjadi data ringkasan pada data warehouse dengan menggunakan OLAP, sehingga dapat menyajikan informasi yang menjelaskan mengenai proses pengelolaan sistem business intelligence didalam Universitas [10]. Data Warehouse atau disingkat DW merupakan basisdata relasional yang didesain lebih kepada query dan analisa dari pada proses transaksi, dan biasanya mengandung history data dari proses transaksi dan bisa juga data dari sumber lainnya. Data Warehouse dapat juga dikatakan sebagai tempat penyimpanan ringkasan dari data historis yang seringkali diambil dari basisdata terpisah departemen, organisasi atau perusahaan, data warehouse mempunyai sifat berorientasi subyek, terintegrasi, time-variant yang dapat digunakan dalam mendukung proses pengambilan keputusan [9][11]. Tujuan utama dari perancangan sebuah data warehouse, yaitu untuk menyatukan data ke dalam sebuah tempat penyimpanan. Pengguna (user) dapat dengan mudah menjalankan query sehingga laporan yang dihasilkan didapat dengan mudah, dan dapat juga digunakan untuk melakukan analisis. Salah satu keuntungan dari penggunaan data warehouse adalah dapat meningkatkan efektifitas didalam pengambilan keputusan, karena merupakan repositori utama untuk ketersediaan data dalam pengembangan business intelligence dan decision support systems. On-Line Analytical Processing atau yang biasa disebut dengan OLAP merupakan suatu metode khusus untuk melakukan analisis terhadap data-data yang didalam penelitian ini nantinya akan digunakan untuk menyimpan data-data penelitian dari Perguruan Tinggi XYZ yang disimpan didalam media penyimpanan berupa basis data/database yang nantinya berada pada server, untuk dapat dibuat laporan analisis yang disesuaikan dengan kebutuhan [7]. On-Line Analytical Process merupakan sebuah teknologi didalam sistem business intelligence yang memungkinkan seorang analis, eksekutif, dan pimpinan secara bersama-sama dapat mengakses datadata secara real-time, konsisten, dan interaktif dengan berbagai variasi dan visualisasi tinjauan informasi yang dapat disesuaikan dengan kebutuhan dimana setiap baris data dapat di transformasikan untuk merefleksikan dimensi perusahaan, organisasi, maupun perguruan tinggi sehingga dapat dengan mudah untuk dipahami oleh pengguna [9].

\section{PERANCANGAN SISTEM}

Gambar.1 dibawah ini menunjukkan diagram alir dari penelitian yang dilakukan. 


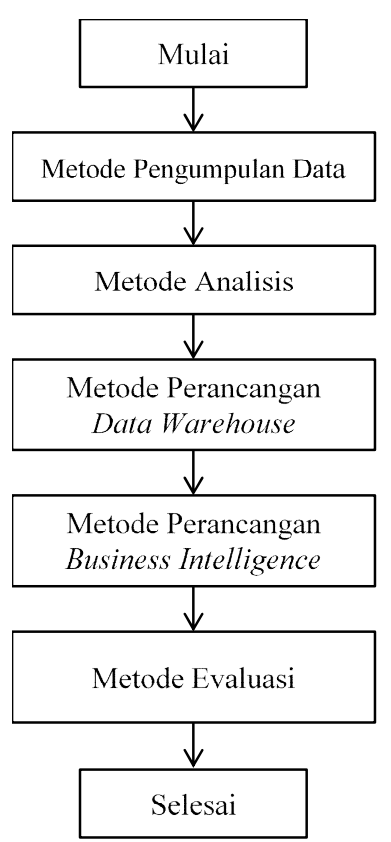

Gambar 1 Diagram Alir Peneltian.

Dengan adanya pengembangan dan implementasi dari sistem business intelligence yang dilakukan diharapkan menjadi salah satu solusi yang dinilai cukup potensial untuk dapat memecahkan masalah tersebut diatas, sehingga menjadi salah satu tools yang bisa digunakan untuk melakukan analisis dan monitoring terhadap data-data penelitian yang di perlukan untuk pencapaian target nilai akreditasi.

\subsection{Pengumpulan Data}

Tahap pertama dari penelitian ini yaitu pengumpulan data, yang bertujuan untuk memperoleh data dan informasi yang dibutuhkan didalam penelitian ini, yaitu melalui observasi, wawancara, studi literarur, dan data borang akreditasi.

Observasi langsung terhadap bisnis proses yang ada di Perguruan Tinggi XYZ untuk dapat menentukan kebutuhan aplikasi yang akan dirancang yang dapat memenuhi kebutuhan pada sistem yang sedang berjalan. Wawancara terhadap pengguna sehubungan dengan bisnis proses yang ada di Perguruan Tinggi XYZ agar dapat mengetahui kebutuhan informasi yang diperlukan dalam merancang sistem business intelligence. Melakukan Studi literatur yang berhubungan dengan penelitian yang akan dilakukan baik itu dari buku-buku, jurnal ilmiah, artikel ilmiah, maupun dari penelitian yang telah dilakukan sebelumnya oleh orang lain yang berhubungan dengan penelitian yang akan dilakukan. Pengumpulan data dari borang akreditasi standar 7 untuk data penelitian dan laporan penelitian yang pernah dibuat sebelumnya di Perguruan Tinggi XYZ.

\subsection{Analisis}

Tahap berikutnya dari penelitian ini adalah analisis, yang bertujuan melakukan analisis untuk mengidentifikasi dan memberi prioritas kebutuhan business information mana yang akan membawa keuntungan maksimal bagi perusahaan sebelum memulai tahap perancangan [12].

Business intelligence opportunity analysis $\mathrm{di}$ dalam penelitian ini terdiri dari business driver, business strategy goal and objectives, value disciplines, core business process, business value.

\subsection{Perancangan Data Warehouse}

Tahap berikutnya dari penelitian ini adalah perancangan data warehouse. Perancangan data warehouse yang akan digunakan didalam penelitian ini, yaitu dengan menerapkan nine-step methodology yang dianjurkan oleh Ralph Kimball [9].

Sembilan langkah metodologi yang digunakan untuk perancangan data warehouse didalam penelitian ini meliputi choosing the process, choosing the grain, identifying and conforming the dimensions, choosing the facts, storing pre-calculation in the fact table, rounding out the dimensions tables, choosing the duration of the databases, tracking slowly changing dimensions, deciding the physical design.

\subsection{Perancangan Business Intelligence}

Tahap berikutnya dari penelitian ini yaitu tahap perancangan sistem business intelligence. Perancangan business intelligence yang digunakan didalam penelitian ini mengadopsi perancangan business intelligence yang dianjurkan oleh Carlo Vercellis [8].

Dalam mengembangkan sebuah business intelligence didalam sebuah perusahaan terdapat 4 fase atau tahapan-tahapan utama yang harus dilakukan, yaitu meliputi analysis, design, planning, dan yang terakhir implementation and control.

\subsection{Evaluasi}

Tahap kedelapan dari penelitian ini yaitu tahap evaluasi untuk sistem business intelligence yang telah dibuat. Evaluasi yang dimaksud yaitu evaluasi untuk sistem business intelligence yang dibuat, dengan tujuan untuk mengevaluasi apakah tujuan dari tesis tercapai, dan juga untuk membandingkan antara sistem business intelligence yang dibuat dengan sistem yang 
sebelumnya telah ada atau sistem yang sedang berjalan (existing). Metode evaluasi ini dilakukan dengan cara interview langsung terhadap operator yang merupakan pengguna (user) dari sistem business intelligence yang akan dibuat.

\section{IMPLEMENTASI DAN PENGUJIAN}

Kondisi sistem yang berjalan saat ini di Perguruan Tinggi XYZ yaitu laporan tentang data-data penelitian belum mempunyai database dan hanya dihasilkan langsung dengan file yang berbentuk excel, dan setiap program studi mempunyai format yang berbeda-beda. Oleh karena itu dibuatkan terlebih dahulu database penelitian yang diberi nama $d b$ Penelitian dengan menggunakan Microsoft Access.

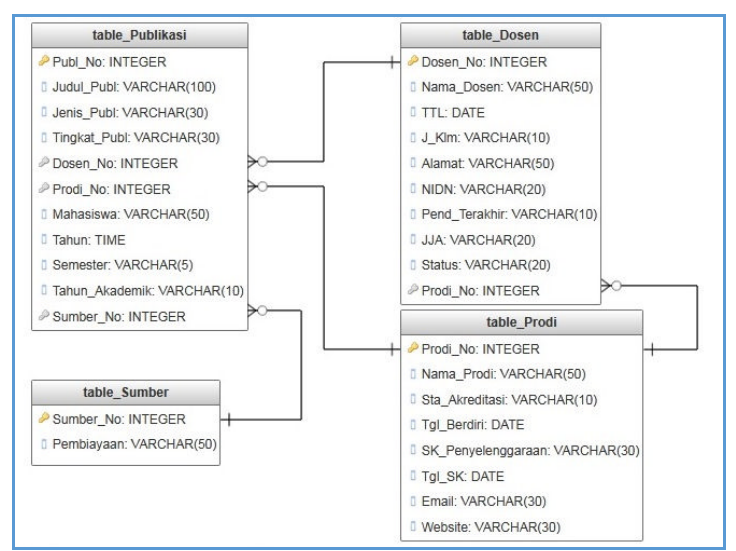

Gambar 2 ERD Database db_Penelitian.

Pada gambar.2 diatas memperlihatkan Entity Relationship Diagram (ERD) dari database $d b$ Penelitian.

Sebelum memulai proses dari ETL maka terlebih dahulu melakukan proses pemindahan data dari database operasional OLTP yaitu $d b$ Penelitian kedalam data warehouse Penelitian. Didalam membuat data warehouse Penelitian, yaitu dengan menggunakan model star schema yang terdiri dari beberapa tabel dimensi dan satu tabel fakta. Tabel dimensi dan tabel fakta yang akan dibuat, disesuaikan dengan ketersediaan data seperti pada gambar.2. Gambar.3 dibawah ini memperlihatkan model star schema yang akan dipergunakan didalam pengembangan data warehouse penelitian.

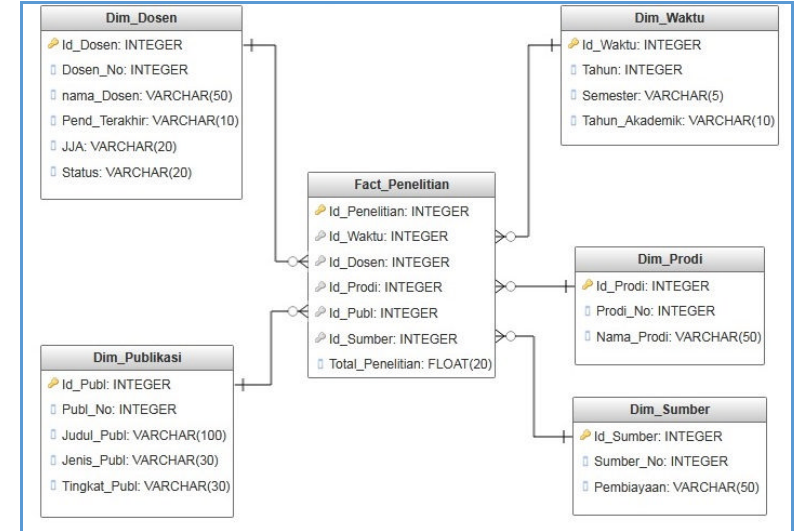

Gambar 3 Model Star Schema dari Data warehouse

\subsection{Implementasi Perancangan Data Warehouse.}

Data-data penelitian yang digunakan untuk implementasi dari perancangan data warehouse berasal dari data yang dikumpulkan melalui data borang standar 7 yang dibuat dengan Ms.Excell \& Ms.Access. Setelah itu dibuat database operasional yang dimasukkan oleh sebuah job yang berisi kumpulan proses ETL (Extract, Transform, Load) dari masing-masing tabel dimensi dan tabel fakta, seperti dijelaskan dibawah ini.

a. Proses ETL tabel dimensi dosen.

Proses tabel dimensi dosen bertujuan untuk membuat dimensi Dim_Dosen yang menampilkan data penelitian berdasarkan nama dosen tertentu yang ada di Peruguruan Tinggi XYZ. Gambar.4 dibawah ini memperlihatkan proses ETL dari Dim_Dosen.

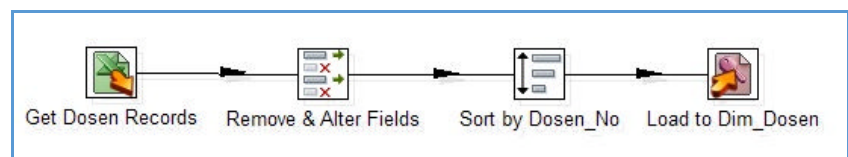

Gambar 4 Proses ETL Dim_Dosen.

b. Proses ETL tabel dimensi prodi.

Proses tabel dimensi prodi bertujuan untuk membuat dimensi Dim_Prodi yang menampilkan data penelitian berdasarkan Program Studi tertentu yang ada di Perguruan Tinggi XYZ. Gambar.5 dibawah ini memperlihatkan proses ETL dari Dim_Prodi.

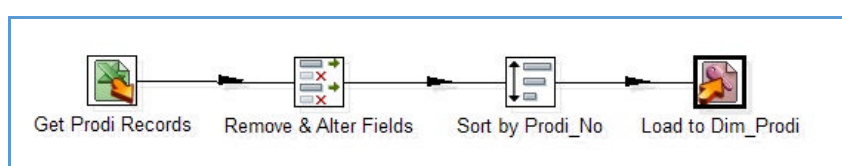

Gambar 5 Proses ETL Dim_Prodi. 
c. Proses ETL tabel dimensi sumber.

Proses tabel dimensi sumber bertujuan untuk membuat dimensi Dim_Sumber yang menampilkan data penelitian berdasarkan sumber dana kegiatan penelitian tersebut. Gambar.6 dibawah ini memperlihatkan proses ETL dari Dim_Sumber.

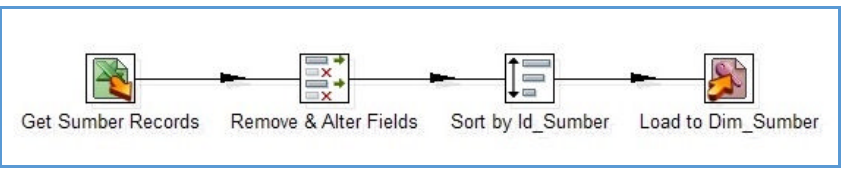

Gambar 6 Proses ETL Dim Sumber.

d. Proses ETL tabel dimensi publikasi.

Proses tabel dimensi publikasi bertujuan untuk membuat dimensi Dim_Publikasi yang menampilkan data publikasi yang ada di Perguruan Tinggi XYZ. Gambar.7 dibawah ini memperlihatkan proses ETL dari Dim_Publikasi.

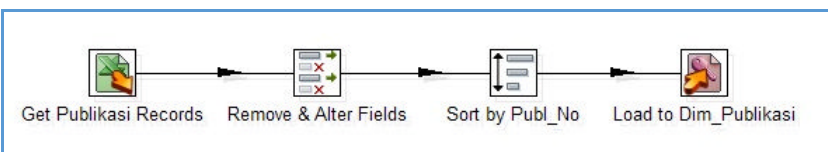

Gambar 7 Proses ETL Dim_Publikasi.

e. Proses ETL tabel dimensi waktu.

Proses tabel dimensi waktu untuk membuat dimensi Dim Waktu yang bertujuan untuk membentuk variabel year, month, dan day yang merepresentasikan waktu dari publikasi. Kemudian nilai dari variabelvariabel tersebut dimasukkan ke dalam tabel Dim_Waktu. Dimensi Dim_Waktu bertujuan untuk menampilkan data publikasi perbulan maupun pertahun. Gambar.8 dibawah ini memperlihatkan proses ETL dari Dim_Waktu.

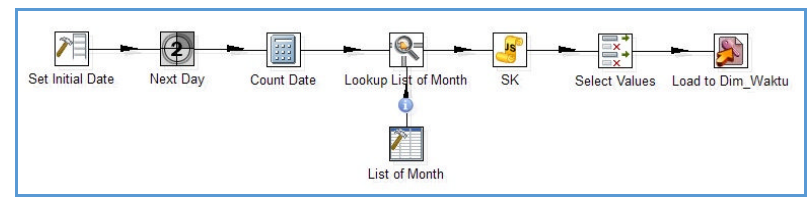

Gambar 8 Proses ETL Dim_Waktu.

f. Proses ETL tabel fakta penelitian.

Proses tabel fakta penelitian bertujuan untuk membuat Fact_Penelitian yang melibatkan beberapa langkah lookup table kepada seluruh tabel dimensinya untuk mengisikan kunci tamu pada tabel fakta serta memasukkan besaran yang merupakan fakta pada star schema dari Data Warehouse Penelitian. Gambar.9 dibawah ini memperlihatkan proses ETL dari Fact Penelitian.

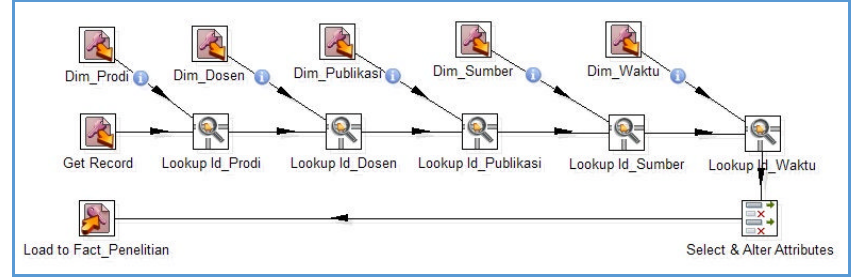

Gambar 9 Proses ETL Fact Penelitian.

4.2 Implementasi Perancangan OLAP Analysis.

Implementasi dari perancangan OLAP Analysis ini nantinya dapat digunakan untuk membuat laporan dan dapat di analisis secara OLAP (On-Line Analytical Processing) dengan menghubungkan antara tabel fakta dan dimensi. Cube PenelitianModels dibuat dengan tujuan untuk memodelkan data, sehingga data penelitian dapat dianalisis dari berbagai dimensi.

a. Hirarki Dim_Waktu.

Shared dimension dari Dim_Waktu menggunakan tabel dim_waktu dengan tipe dimensi yaitu TimeDimension. Gambar.10 memperlihatkan attribute dari hierarchy pada Dim_Waktu.

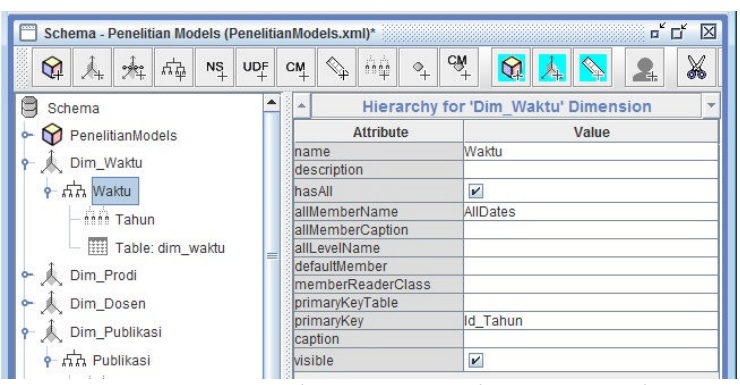

Gambar 10 Attribute Hierarchy Dim Waktu.

b. Hirarki Dim_Prodi.

Shared dimension dari Dim_Prodi menggunakan tabel dim_prodi dengan tipe dimensi yaitu StandardDimension. Gambar.11 memperlihatkan attribute dari hierarchy pada Dim_Prodi.

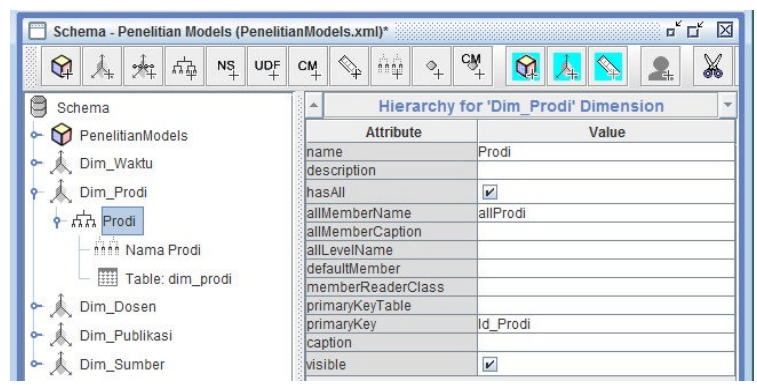

Gambar 11 Attribute Hierarchy Dim_Prodi.

c. Hirarki Dim Dosen.

Shared dimension dari Dim Dosen menggunakan tabel dim_dosen dengan tipe dimensi yaitu StandardDimension. Gambar.12 
memperlihatkan attribute dari hierarchy pada Dim_Dosen.

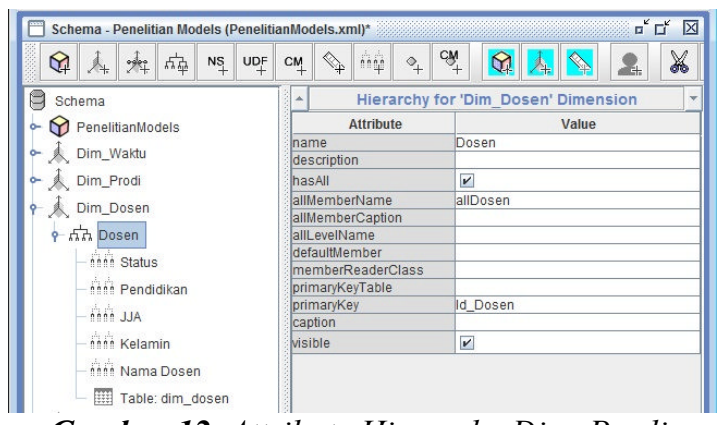

Gambar 12 Attribute Hierarchy Dim Prodi.

d. Hirarki Dim_Publikasi.

Shared dimension dari Dim Publikasi menggunakan tabel dim publikasi dengan tipe dimensi yaitu StandardDimension. Gambar.13 memperlihatkan attribute dari hierarchy pada Dim_Publikasi.

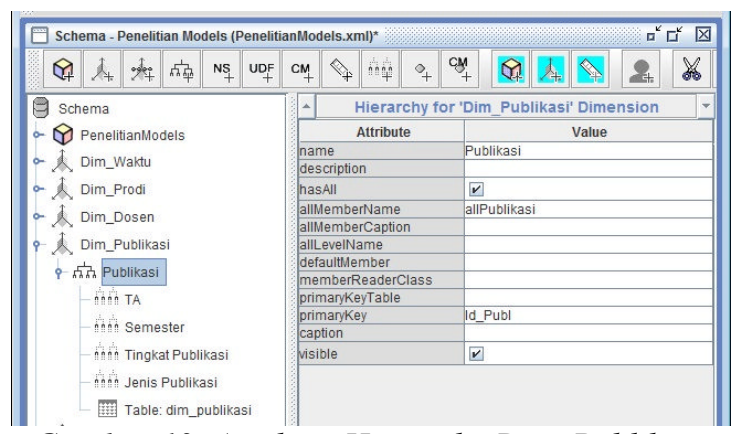

Gambar 13 Attribute Hierarchy Dim Publikasi.

e. Hirarki Dim_Sumber.

Shared dimension dari Dim Sumber menggunakan tabel dim sumber dengan tipe dimensi yaitu StandardDimension. Gambar.14 memperlihatkan attribute dari hierarchy pada Dim_Sumber.

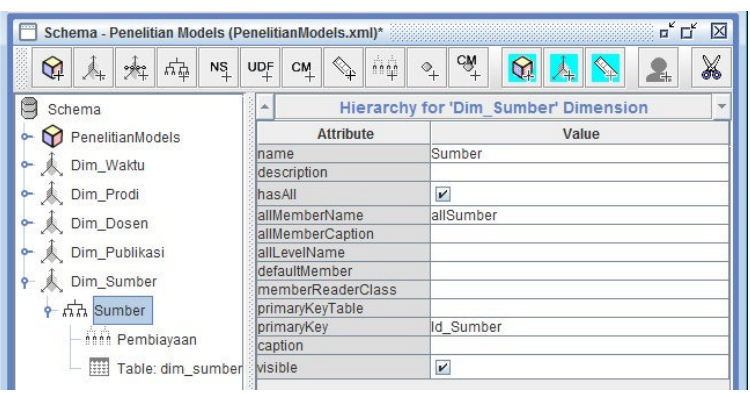

Gambar 14 Attribute Hierarchy Dim_Sumber. f. Cube PenelitianModels.

Setelah definisi untuk shared dimension selesai, maka langkah selanjutnya adalah membuat \& mendefinisikan Cube PenelitianModels yang merupakan model data multidimensi, yang nantinya akan digunakan untuk proses analisis pada data penelitian. Tabel utama dari cube PenelitianModels adalah tabel fakta fact penelitian. Gambar.15 memperlihatkan attribute dari Cube Penelitian Models.

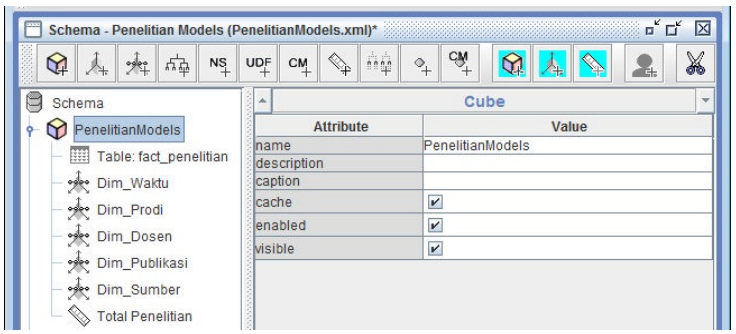

Gambar 15 Attribute Cube PenelitianModels.

4.3 Implementasi Perancangan Report.

Report yang diinginkan berdasarkan desain tersebut yaitu agar user mendapatkan data-data penelitian dan juga total penelitian yang divisualisasikan melalui pie chart, karena memang belum pernah ada database untuk penelitian di Perguruan Tinggi XYZ. Gambar.16 menampilkan hasil dari report yang didesain dengan menggunakan $P R D$.

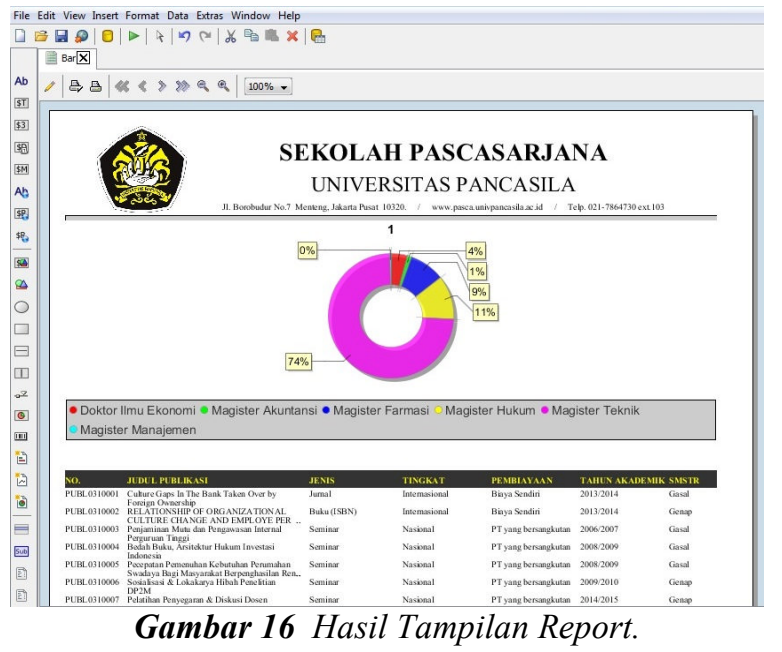


4.4 Implementasi Perancangan Dashboard.

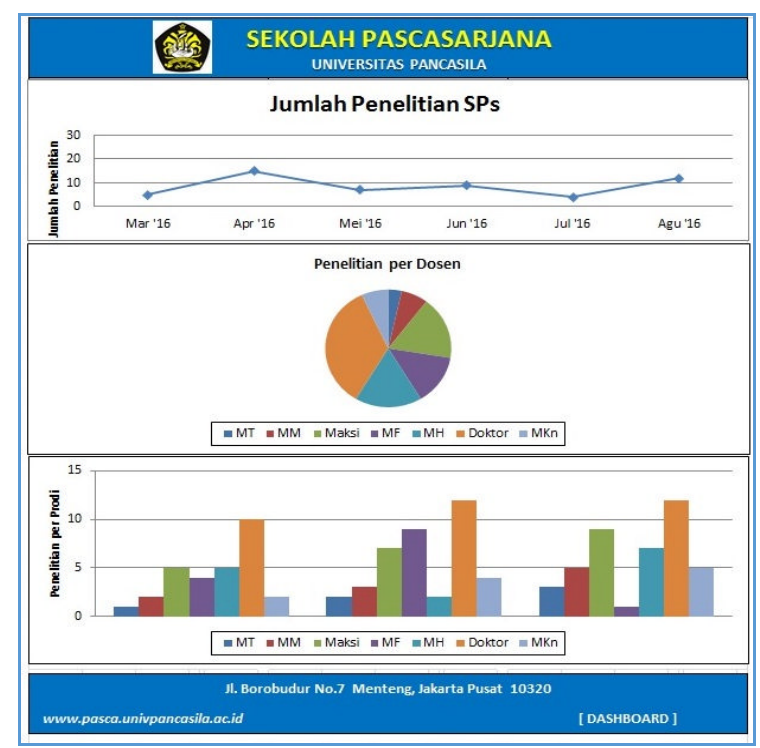

Gambar 17 Halaman Utama Dashboard Business Intelligence.

Perancangan dashboard SPs menggunakan CDE (Community Dashboard Editor). Untuk membuat dashboard memerlukan penggabungan beberapa tabel untuk membentuk sebuah relasi, yaitu dari tabel-tabel dimensi dan tabel fakta. Gambar.17 dibawah ini memperlihatkan tampilan utama dari halaman dashboard.

a. Dashboard Total Publikasi.

Dashboard ini menunjukkan jumlah total publikasi yang disajikan dalam bentuk pie chart. Setiap tahun publikasi yang diklik akan menampilkan pop-up yang menampilkan informasi tentang prodi yang melakukan publikasi pada tahun tersebut. Gambar.18 memperlihatkan dashboard total publikasi pada dashboard SPs.

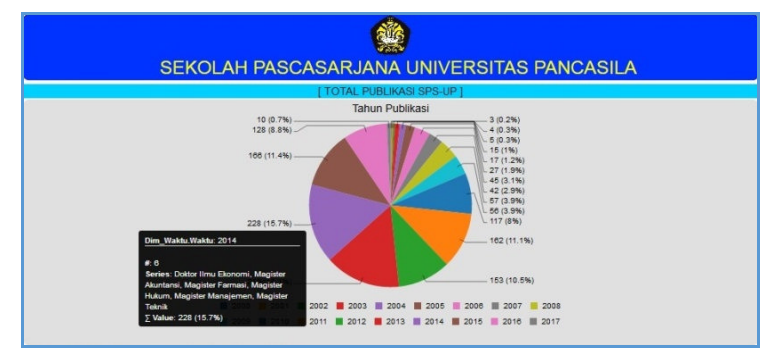

Gambar 18 Dashboard Total Publikasi Semua Program Studi.

b. Dashboard Program Studi.

Dashboard ini menunjukkan jumlah total publikasi per tahun berdasarkan program studi yang disajikan dalam bentuk line chart. Setiap line yang diklik akan menampilkan pop-up yang menampilkan informasi tentang prodi dan jumlah publikasi pada tahun tersebut. Gambar.19 memperlihatkan dashboard berdasarkan program studi pada dashboard SPS.

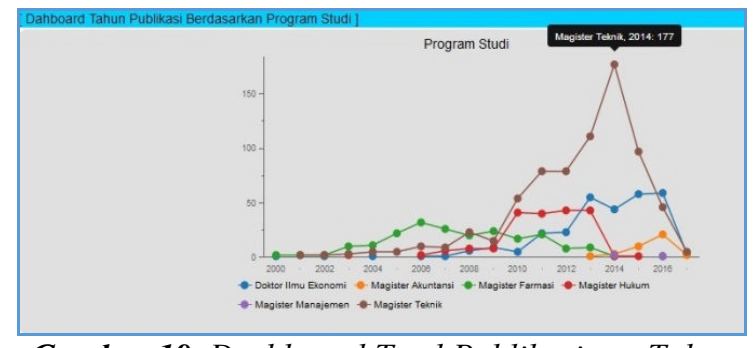

Gambar 19 Dashboard Totsl Publikasi per Tahun Berdasarkan Program Studi.

c. Dashboard Sumber Dana.

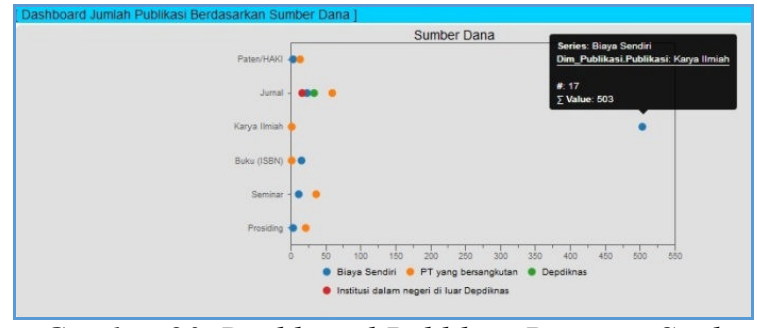

Gambar 20 Dashboard Publikasi Program Studi Berdasarkan Sumber Dana.

Dashboard ini menunjukkan jenis publikasi berdasarkan sumber dana yang disajikan dalam bentuk dot chart. Setiap titik yang diklik akan menampilkan pop-up yang menampilkan informasi tentang jumlah publikasi berdasarkan jenis publikasi dan sumber dana nya. Gambar.20 memperlihatkan dashboard berdasarkan sumber dana pada dashboard SPs.

d. Dashboard Tingkat Publikasi.

Dashboard ini menunjukkan total publikasi berdasarkan tingkat publikasi yang disajikan dalam bentuk bar chart. Setiap bar yang diklik akan menampilkan pop-up yang menampilkan informasi tentang jumlah publikasi dan tingkat publikasi dari program studi. Gambar.21 memperlihatkan dashboard berdasarkan tingkat publikasi pada dashboard SPS.

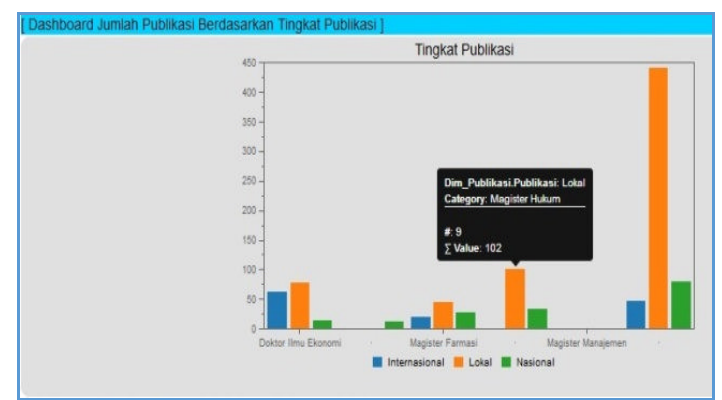

Gambar 21 Dashboard Total Publikasi Berdasarkan Tingkat Publikasi. 
e. Dashboard Jenis Publikasi.

Dashboard ini menunjukkan total publikasi berdasarkan jenis publikasi yang disajikan dalam bentuk bar chart. Setiap bar yang diklik akan menampilkan pop-up yang menampilkan informasi tentang jumlah publikasi dan jenis publikasi dari program studi. Gambar.22 memperlihatkan dashboard berdasarkan jenis publikasi pada dashboard SPS.

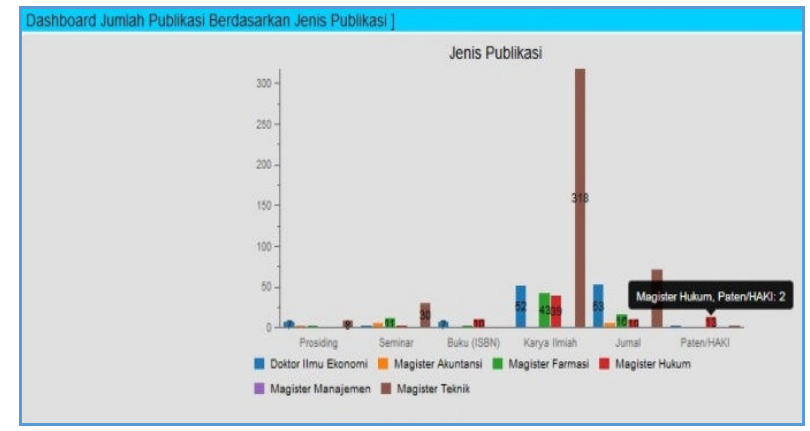

Gambar 22 Dashboard Total Publikasi Berdasarkan Jenis Publikasi.

f. Dashboard Jenjang Jabatan Akademik.

Dashboard ini menunjukkan jumlah total publikasi berdasarkan jenjang jabatan akademik yang disajikan dalam bentuk pie chart. Setiap bagian yang diklik akan menampilkan pop-up yang menampilkan informasi tentang jenjang jabatan akademik dari dosen yang melakukan publikasi. Gambar.23 memperlihatkan dashboard berdasarkan JJA pada dashboard SPs.

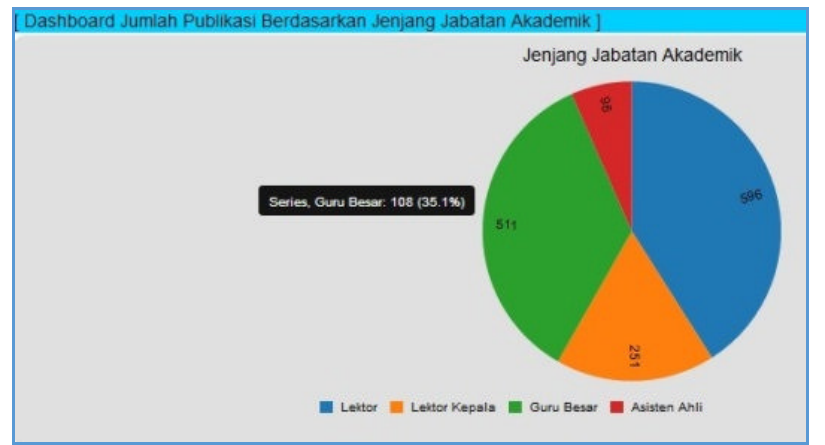

Gambar 23 Dashboard Total Publikasi Berdasarkan Jenjang Jabatan Akademik Dosen.

\section{g. Dashboard Status Dosen.}

Dashboard ini menunjukkan jumlah total publikasi berdasarkan status dosen yang disajikan dalam bentuk pie chart. Setiap bagian yang diklik akan menampilkan pop-up yang menampilkan informasi tentang status dari dosen yang melakukan publikasi. Gambar.24 memperlihatkan dashboard berdasarkan status dosen pada dashboard SPs.

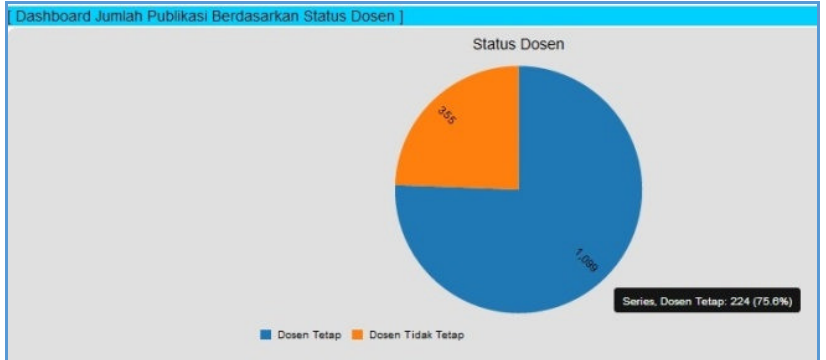

Gambar 24 Dashboard Total Publikasi Berdasarjan Status Dosen.

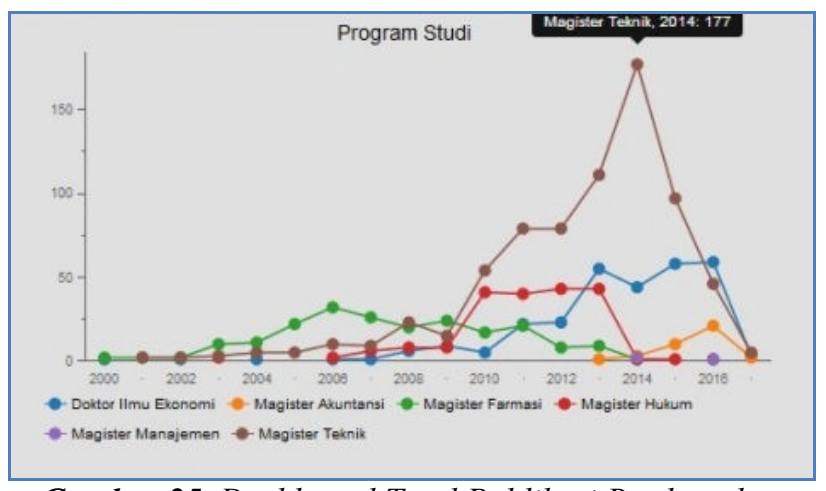

Gambar 25 Dashboard Total Publikasi Berdasarkan Tahun Publikasi.

Tampilan dashboard pada gambar.25 menunjukkan bahwa publikasi yang dilakukan paling banyak yaitu pada tahun $2013 \& 2014$, dan dilakukan oleh dosen-dosen yang berada pada program studi Magister Teknik dan Doktor Ilmu Ekonomi. Oleh karena itu Perguruan Tinggi XYZ harus mendorong program studi lain agar dapat meningkatkan jumlah penelitiannya.

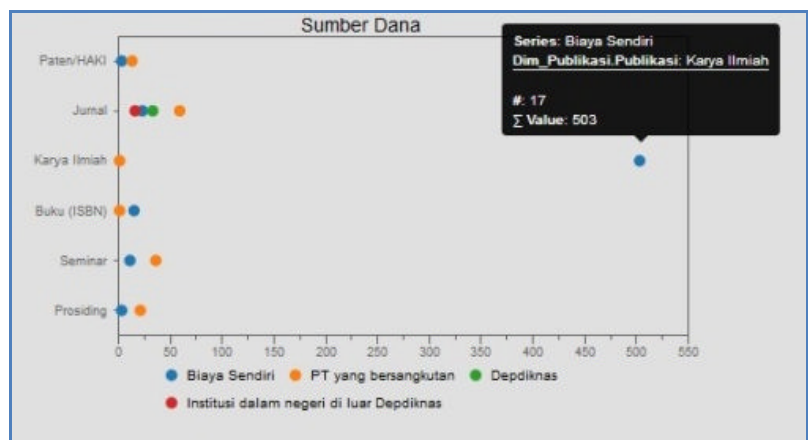

Gambar 26 Dashboard Jumlah Publikasi Berdasarkan Sumber Dana dan Jenis Publikasi nya.

Tampilan dashboard pada gambar.26 menunjukkan bahwa publikasi yang paling banyak dengan jenis Karya Ilmiah dengan sumber dana Biaya Sendiri. Oleh karena itu Perguruan Tinggi XYZ harus menambah anggaran untuk membiayai penelitianpenelitian, sehingga dapat meningkatkan kualitas dan kuantitas penelitian yang ada. 


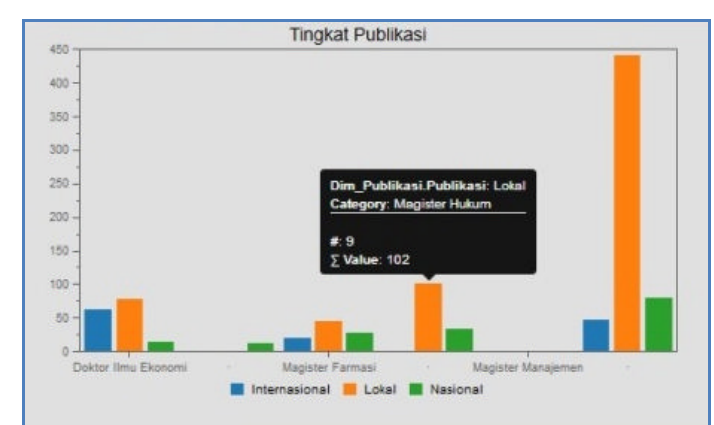

Gambar 27 Dashboard Jumlah Publikasi Berdasarkan Tingkat Publikasi dan Program Studi.

Tampilan dashboard pada gambar.27 menunjukkan bahwa jumlah publikasi terbanyak untuk tingkat publikasi Lokal dihasilkan oleh program studi Magister Teknik, sedangkan jumlah publikasi terbanyak untuk tingkat publikasi Internasional dihasilkan oleh program studi Doktor Ilmu Ekonomi. Oleh karena itu Perguruan Tinggi XYZ harus mendorong kepada dosen agar meningkatkan publikasi pada level tingkat internasional.

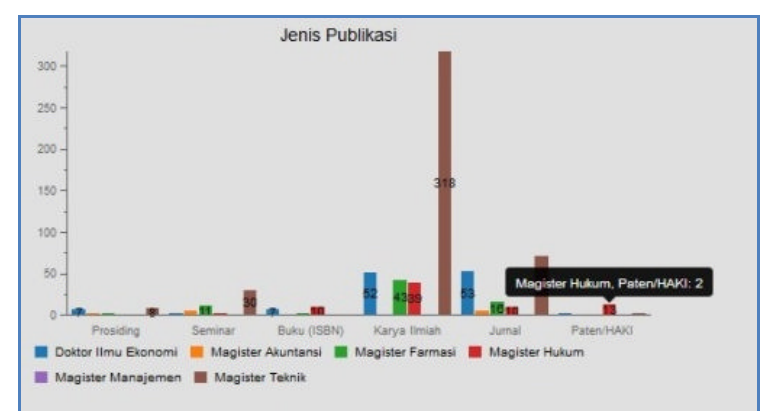

Gambar 28 Dashboard Jumlah Publikasi Berdasarkan Program Studi dan Jenis Publikasi nya.

Tampilan dashboard pada gambar.28 menunjukkan bahwa penelitian dengan jenis publikasi Paten/HAKI jumlahnya masih sangat sedikit sehingga perlu ditingkatkan, sedangkan penelitian yang terbanyak yaitu jenis publikasi Karya Ilmiah yang merupakan penelitian yang dihasilkan melalui hasil dari tesis maupun disertasi bersama dengan mahasiswa.

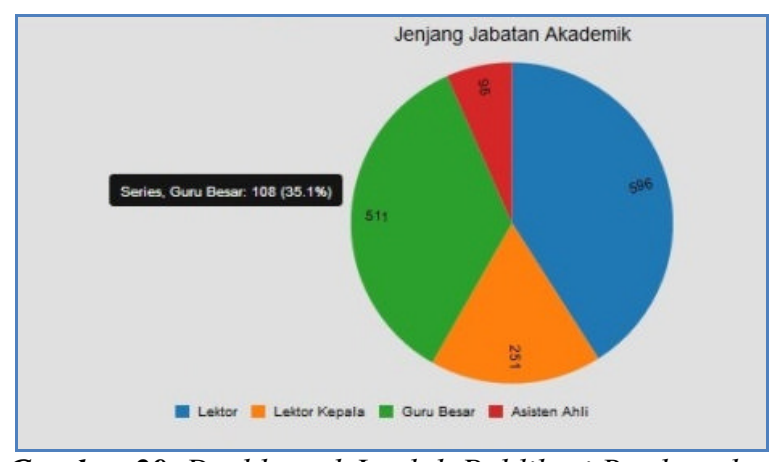

Gambar 29 Dashboard Jumlah Publikasi Berdasarkan Jenjang Jabatan Akademik.
Tampilan dashboard pada gambar.29 menunjukkan bahwa jumlah publikasi terbanyak dihasilkan oleh dosen yang mempunyai jenjang jabatan akademik Lektor, sedangkan dosen dengan jenjang jabatan akademik Asisten Ahli menghasilkan jumlah publikasi yang paling sedikit. Oleh karena itu Perguruan Tinggi XYZ harus memotivasi kepada dosen-dosen yang masih mempunyai jenjang jabatan akademik sebagai Asisten Ahli dan Lektor agar terus meningkatkan kepangkatannya salah satunya yaitu melalui penelitian yang luaran nya menghasilkan publikasi.

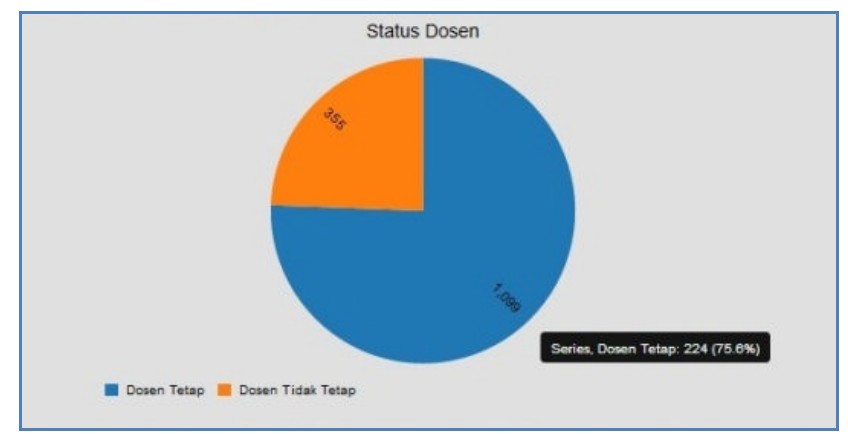

Gambar 30 Dashboard Jumlah Publikasi Berdasarkan Status Dosen.

Tampilan dashboard pada gambar.30 menunjukkan bahwa jumlah publikasi paling banyak dilakukan oleh dosen yang berstatus Dosen Tetap.

\section{SIMPULAN}

Kesimpulan dari hasil penelitian ini adalah dengan adanya data warehouse data-data penelitian yang dirancang dengan menggunakan PDI (Pentaho Data Integration), sangat membantu didalam mengumpulkan data-data penelitian dari yang semula data-data penelitian tersebut belum mempunyai database dan hanya sebagai data OLTP (Online Transactional Processing) sehingga dapat dijadikan sebagai data OLAP (Online Analysis Processing) sehingga dianalisis dengan menggunakan Mondrian OLAP.

Selain itu dalam penelitian ini untuk reporting data-data penelitian yang dirancang dengan menggunakan PRD (Pentaho Report Designer), sangat membantu didalam membuat laporan penelitian dan dapat disesuaikan dengan kebutuhan, sehingga masalah yang sering terjadi dalam hal kebergantungan dalam perolehan laporan diharapkan tidak terjadi kembali.

Dashboard penelitian yang dirancang dengan menggunakan Pentaho CDE (Community Dashboard Editor), sangat membantu pimpinan didalam menganalisis data untuk mempelajari tren penelitian 
yang dilakukan di Perguruan Tinggi XYZ, serta dapat dijadikan untuk mendukung pengambilan keputusan dan dapat juga sebagai pengukur kinerja dosen.

\section{KEPUSTAKAAN}

[1] B. M. Drake and A. Walz, "Evolving Business Intelligence and Data Analytics in Higher Education," New Dir. Institutional Res., vol. 2018, no. 178, pp. 39-52, 2018.

[2] Henderi and E. Winarko, "Rancangan Framework Business Intelligence Pada Perguruan Tinggi," Semin. Nas. Mat. dan Apl. 2013, no. June 2013, pp. 406-411, 2013.

[3] H. P. Poerbo, "Purwarupa Data Warehouse Pada Sistem Informasi Manajemen Perguruan Tinggi Studi Kasus: STIKOM Surabaya,” pp. $1-13$.

[4] B. A. N. P. T. BAN PT, "Buku II: Standar dan Prosedur," 2010.

[5] Henderi, I. Handayani, and M. A. Dewi, "Business Intelligence Development Model Using Star Schema Methodology," vol. 5, no. 3, pp. 233-250, 2012.

[6] Salman, "Rancangan Sistem Business Intelligence Sebagai Pendukung Pengambilan Keputusan Di Amikom Mataram.," CommIT (Communication Inf. Technol. J., no. 2017, 2017.
[7] Z. Arifin and A. Sugiharto, "Rancang Bangun Sistem Business Intelligence Universitas Sebagai Pendukung Pengambilan Keputusan Akademik," J. Sist. Inf. Bisnis, vol. 3, no. 1, pp. 30-40, 2013.

[8] C. Vercellis, Business Intelligence: Data Mining and Optimization for Decision Making, 1st ed. Italy: Wiley Publishing, Inc., 2009.

[9] R. Kimball and M. Ross, The Data Warehouse Lifecycle Toolkit, Relentlessly Practical Tools for Data Warehousing and Business Intelligence. Wiley Publishing, Inc., 2010.

[10] C. D. 'Aquila, F. Di Tria, E. Lefons, and F. Tangorra, "Business Intelligence Applications for University Decision Makers," WSEAS Trans. Comput., vol. 7, no. 7, pp. 1010-1019, 2017.

[11] W. H. Inmon, Building The Data Warehouse, Fourth Edi. Indiana: Wiley Publishing, Inc., 2005.

[12] S. Williams and N. Williams, The Profit Impact of Business Intelligence. San Fransisco: Morgan Kaufmann Publishers, 2007. 